\title{
RANCANG BANGUN APLIKASI DETEKSI TEPI CITRA DIGITAL MENGGUNAKAN ALGORITMA PREWITT
}

\author{
Ardiansyah Putra1, Volvo Sihombing ${ }^{2}$, Mustafha Haris Munandar ${ }^{3}$ \\ 1,2,3 Fak. Sains dan Teknologi, Univ.Labuhanbatu \\ email: ardyansaputra21@yahoo.com, volvolumbantoruan@gmail.com, \\ harismunandaaar@gmail.com
}

\begin{abstract}
Edge detection is one of the algorithms used in Digital Image Processing. This algorithm serves to identify the lineledge of the image object to highlight the boundary lines of the image information. Edge is a set of connected pixels (connected pixels) that restricts the objects contained in the image. Senses the eye is one that is used by humans to see. However, the human eye has its limitations in capturing the electromagnetic signals. Therefore, created a computer or imaging machine that can capture almost the entire signal elektromagnetic. Imaging machines can work with imagery from sources that do not fit, do not fit or can not be captured by human vision. This is why digital image processing have very wide usefulness. Image processing technology can fit into a variety of fields such as medicine, geology, marine, industrial and others.
\end{abstract}

Keywords: Image, Prewitt, Edge, Java, Netbeans

\section{PENDAHULUAN}

Saat ini seiring dengan berkembangnya pengetahuan dan teknologi yang amat pesat, maka masyarakat pada umumnya akan berhadapan pada dampak kemudahan yang dihasilkan oleh setiap teknologi. Banyak pihak akan berusaha menghadirkan teknologi yang dapat membantu manusia di dalam berbagai sudut kebutuhan, yang salah satu termasuk di dalam nya adalah teknik image processing yang berkembang seiring dengan kreativitas manusia.

Citra adalah sekumpulan informasi yang dapat diolah menjadi sebuah gambar [1]. Pengolahan citra merupakan pemrosesan citra dengan menggunakan komputer yang berfungsi untuk membuat sebuah citra menjadi citra yang kualitasnya lebih baik. Sedangkan defenisi citra sendiri adalah representasi atau tiruan dari suatu benda atau objek. Citra dibagi menjadi dua, yaitu citra analog dan citra digital.

Proses pengolahan citra dapat dilakukan dengan banyak cara, salah satunya adalah dengan cara deteksi tepi. Deteksi tepi salah satu algoritma yang mampu memproses Citra Digital. Algoritma Prewitt dapat mengenali sebuah objek citra yang menampilkan garis tepi dari sebuah obyek. Tepi merupakan sekumpulan pixel yang terkoneksi untuk memberikan tepi kepada obyek. Pengolahan memiliki kemampuan keberadaan tepi dari objek dengan citra [2].

Metode prewitt ini menekankan pembobotan pada piksel-piksel yang lebih dekat. Metode prewitt hampir sama dengan metode sobel dimana metode sobel ini menggunakan HPF yang nilai konstantanya adalah Nol [3]. Dalam penelitian ini ada beberapa objek yang akan di uji dengan metode prewitt yang kemudian hasilnya dibandingkan dengan metode cany, dimana hasil dari kedua metode tersebut nantinya akan dibandingkan untuk mencari nilai terbaik. Penggabungan ke dua metode ini hanya membandingkan nilai pixel setiap objek [4], [5].

Cara kerja dari Algoritma Prewitt dengan cara menghitung hasil maksimum dari suatu kernel konvolusi untuk menemukan orientasi deteksi sisi disekitarnya pada tiap pixel. Algoritma ini juga disebut sebagai edge template matching, karena gambar mengalami proses matching dengan sebuah template yang berupa sisi [6].

Semakin besar tingkat kerapatan objek akan menentukan resolusi dari komponen citra yang dimiliki sebuah objek. Pixel akan sangat mempengaruhi proses kuantitasi semakin besar 
pixel maka semakin besar variasi nilai warnanya yang dihasilkan dan semakin mirip dengan warna objeks aslinya [7], [8], [9].

\section{METODE PENELITIAN}

\section{Perancangan Sistem}

Agar mempermudah pembuatan aplikasi yang akan dibangun maka dibuat Flowchart yang akan mempermudah membaca langkah-langkah dalam metode prewitt yang akan dilakukan di aplikasi yang dibangun.

1. Flowchart

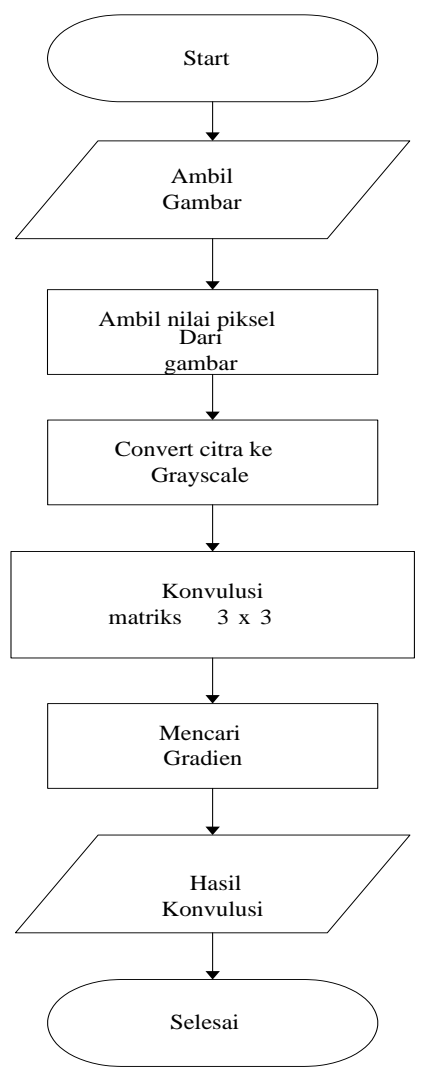

Gambar 1. Alur Flowchart Edge Detection Dengan Algoritma Prewitt

Grayscale merupakan gambar yang memiliki warna yang diubah menjadi keabuan [10]. Format gambar yang digunakan dalam penelitian ini memiliki beberapa ekstensi format gambar, JPG, GIF, PNG[11]. Gambar yang digunakan pada metode Prewitt dan Sobel dalam penelitian ini membandingkan objek gigi, jantung, rumah, paru-paru dan bus. Konvolusi merupakan setiap bagian matrik memiliki koefisien angka [12].

\section{Rancang Masukan}

Rancangan ini digunakan sebagai tampilan awal dari aplikasi yang dibuat antara lain

a) Desain input login

Desain input ini yang akan muncul ketika awal mula menggunakan aplikasi ini dengan memasukkan username dan password agar user bisa secara keseluruhan menjalankan fungsi yang telah dibuat. Berikut pada gambar 2 merupakan tampilan form login.

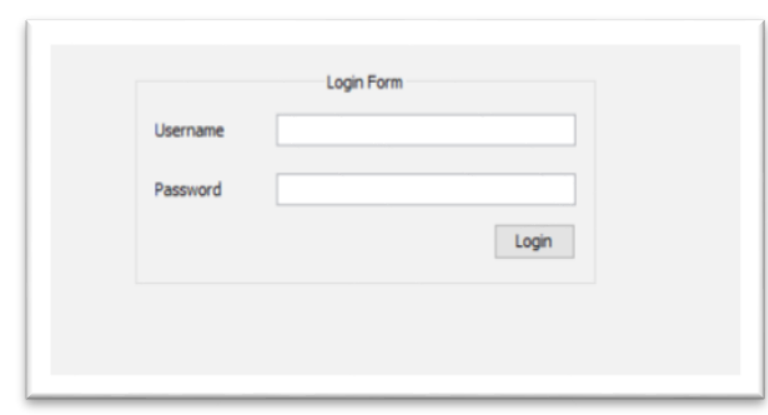

Gambar 2. Desain Form Login

b) Desain Form Input Gambar

Form ini digunakan untuk memasukkan sebuah gambar dan selanjutnya akan dilakukan proses pengolahan citra dari gambar awal dan diubah menjadi prewit. Desain form bisa kita lihat pada gambar 3 .

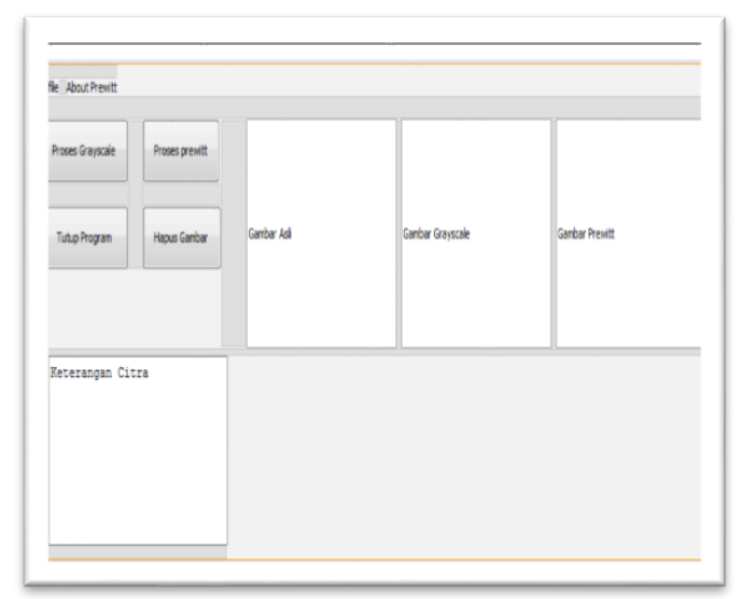

Gambar 3. Desain Form Input Gambar 


\section{HASIL DAN PEMBAHASAN}

Hasil penerapan dari rancangan penelitian ini berupa sebuah sistem atau aplikasi Deteksi Tepi Citra Digital menggunakan Algoritma Prewitt

\section{Form Login}

Untuk menjalankan aplikasi maka user wajib memasukkan username dan password yang telah dirancang pada form ini. Gambar 4 merupakan tampilan untuk login.

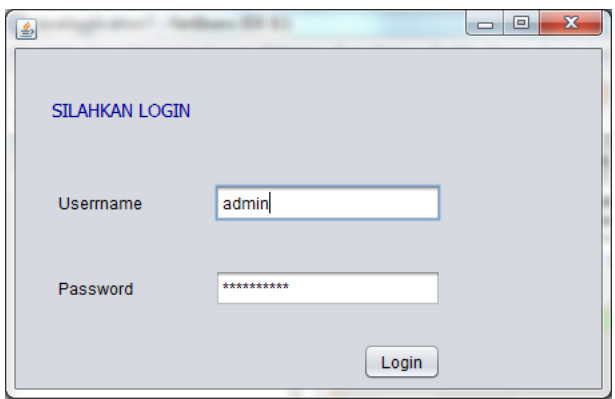

Gambar 4. Tampilan Halaman Login

\subsection{Perancangan dan Analisis}

Di dalam perancangan pembuatan perangkat lunak harus benar-benar teruji baik dan minimnya permasalahan terjadi, dibawah ini akan dilihat persentase penjabaran yang akan di laksanakan untuk mendeteksi tepi dengan Prewitt pada gambar RED, GREEN \& BLUE (RGB).

Dengan prewitt matriks 3x3 kernel $\mathrm{X}$ dan kernel $\mathrm{Y}$ harus konstanta diberikan nilai awal konstanta 1. Nilai warna pixel RED, GREEN, BLUE dari obyek citra akan dikonvolusi dengan sumbu $x$ dan sumbu y selanjutkan akan dilakukan perhitungan gradient setiap pixel. Setelah di konvolusi akan diberikan batas buram atau kabur dari gambar awal yang telah dikonversi, sehingga menghasilkan gambar atau citra deteksi tepi.

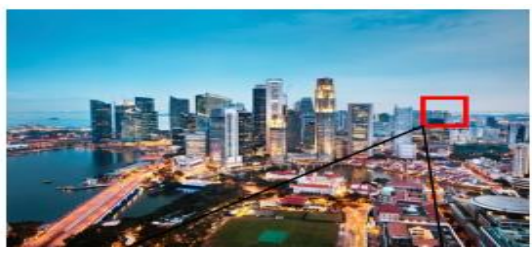

Gambar 5. Citra Gambar
Tabel 1. Nilai Pixel Dari Gambar 7

\begin{tabular}{|c|c|c|c|c|}
\hline 56 & 58 & 59 & 59 & 60 \\
\hline 40 & 43 & 41 & 41 & 41 \\
\hline 33 & 35 & 36 & 36 & 39 \\
\hline 45 & 49 & 51 & 52 & 53 \\
\hline 72 & 82 & 80 & 75 & 76 \\
\hline 69 & 101 & 101 & 94 & 94 \\
\hline 100 & 106 & 106 & 108 & 105 \\
\hline 107 & 116 & 116 & 116 & 106 \\
\hline
\end{tabular}

\subsection{Tahapan Metode Prewitt}

Tahapan yang telah dibuat ialah sebagai berikut

1. pengenalan citra asli akan di deteksi tepinya.

2. Kemudian diubah citra menjadi grayscale.

3. Haluskan citra agar menghilangkan derau dengan filter median.

4. Lakukan operasi prewitt

5. Berikan nilai ambang batas

6. Tampilkan hasil proses prewitt

\subsection{UJI COBA HASIL}

Pengujian dilakukan menggunakan tiga buah obyek citra seperti Gigi, Paru-paru dan Jantung pada manusia. Yang pertama dilakukan adalah memfilter adjust citra atau menyesuaikan kecerahan gambar/citra agar nantinya dihasilkan citra yang lebih baik.

\section{ObyekGigi :}

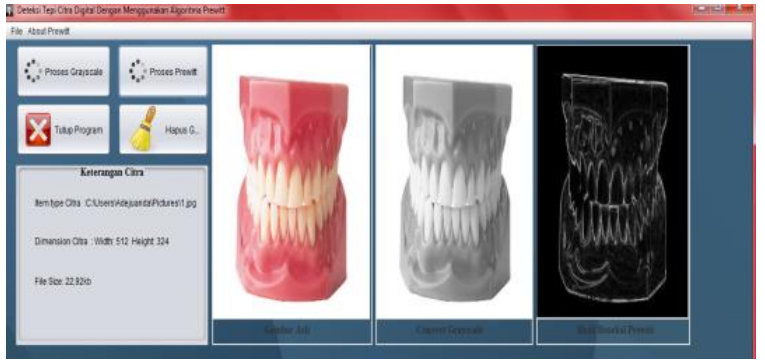

Gambar 6.Obyek Gigi

Hasil dari citra Obyek gigi yang dideteksi tepinya akan ditampilkan semua seperti yang terlihat pada gambar 6 .

\section{Obyek Paru-paru}

Hasil dari citra Objek paru-paru yang dideteksi tepinya akan ditampilkan semua seperti 
yang terlihat pada gambar 7 berikut ini.

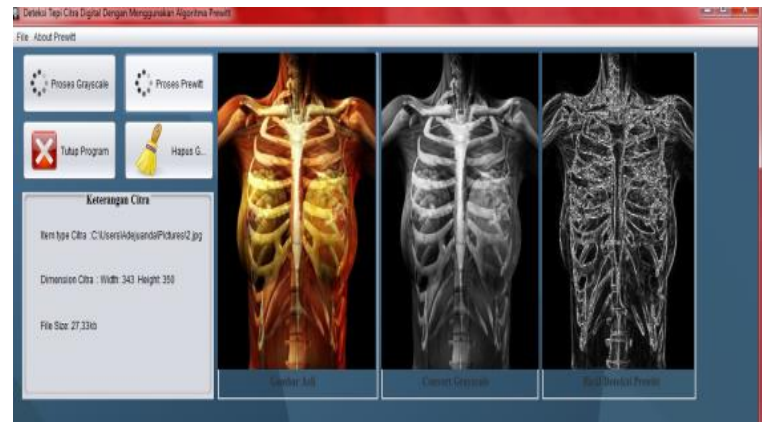

Gambar 7. Obyek Paru-paru

\section{Obyek Jantung}

Hasil dari citra Objek Jantung yang dideteksi tepinya akan ditampilkan semua seperti yang terlihat pada gambar berikut :

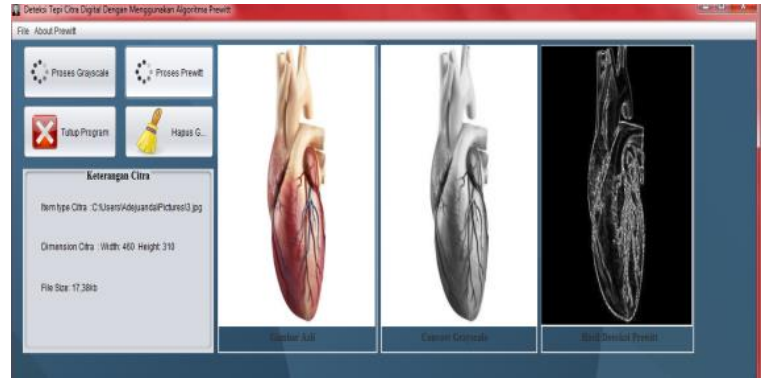

Gambar 8. Obyek Jantung

\subsection{Hasil Uji Coba Perbandingan Algoritma Prewit dan Canny}

Kedua algoritma ini dapat digunakan dalam menguji coba mendeteksi citra digital. Cara pertama setelah mengambil gambar yaitu menjalankan tombol button gray untuk mengubah citra dari warna asli menjadi grayscale. Gambar 9 yaitu tampilan gambar murni yang di konversi ke grayscale.

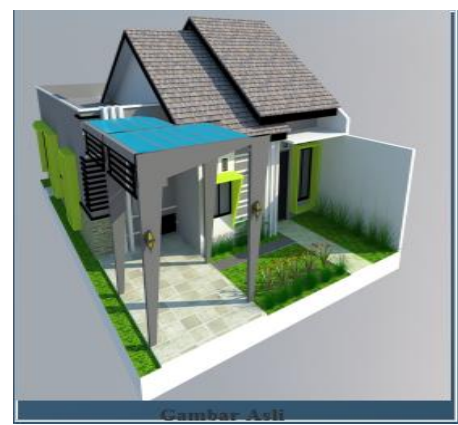

Gambar 9. Citra Asli

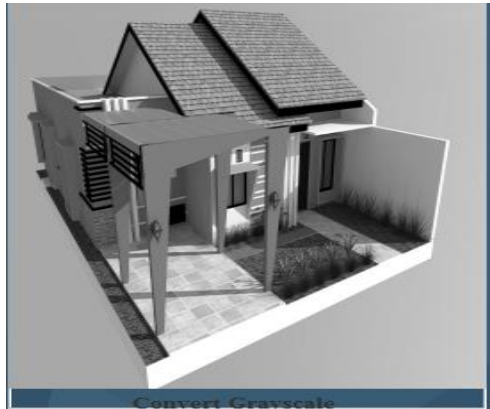

Gambar 10.Hasil Gray

Dengan perbandingan kedua algoritma tersebut dalam mendeteksi tepi objek yang digunakan sebanyak 5 sampel gambar maka hasil output kinerja waktu Prewitt dan Canny nya dapat dilihat di tabel 2.

Tabel 2. Hasil Perbandingan Output Prewitt dan Canny

\begin{tabular}{|c|c|c|c|}
\hline \multirow{2}{*}{ Objek } & \multicolumn{2}{|c|}{ Algoritma } & Hasil \\
\cline { 2 - 4 } Gigi & $\begin{array}{c}\text { Prewitt } \\
\text { second }\end{array}$ & $\begin{array}{c}\text { Canny } \\
01.08 \\
\text { second }\end{array}$ & Prewitt \\
\hline Jantung & $\begin{array}{c}01.10 \\
\text { second }\end{array}$ & $\begin{array}{c}01.12 \\
\text { second }\end{array}$ & Prewitt \\
\hline $\begin{array}{c}\text { Paru- } \\
\text { Paru` }\end{array}$ & $\begin{array}{c}01.12 \\
\text { second }\end{array}$ & $\begin{array}{c}01.14 \\
\text { second }\end{array}$ & Prewitt \\
\hline Rumah & $\begin{array}{c}01.06 \\
\text { second }\end{array}$ & $\begin{array}{c}01.08 \\
\text { second }\end{array}$ & Prewitt \\
\hline Bus & $\begin{array}{c}01.06 \\
\text { second }\end{array}$ & $\begin{array}{c}01.08 \\
\text { second }\end{array}$ & Prewitt \\
\hline
\end{tabular}

Untuk mengetahui hasil kinerja kualitas deteksi Prewitt dan Canny dapat dilihat pada tabel 3.

Tabel 3. Hasil Perbandingan Kualitas Output Prewitt dan Canny

\begin{tabular}{|c|c|c|c|}
\hline \multirow{2}{*}{ Objek } & \multicolumn{2}{|c|}{ Algoritma } & \multirow{2}{*}{ Hasil } \\
\cline { 2 - 3 } & Prewitt & Canny & \\
\hline Gigi & Baik & Lebih Baik & Canny \\
\hline Jantung & Baik & Lebih Baik & Canny \\
\hline Paru-Paru & Baik & Lebih Baik & Canny \\
\hline Rumah & Baik & Lebih Baik & Canny \\
\hline Bus & Baik & Lebih Baik & Canny \\
\hline
\end{tabular}




\section{KESIMPULAN}

Algoritma Prewit ini merupakan algoritma yang tergolong baik dalam melakukan proses deteksi, bisa berformat JPEG, GIF, PNG. Metode logika prewitt dapat diaplikasikan sebagai salah satu pendekteksian tepi. Semakin besar ukuran gambar maka semakin lama untuk mendeteksi tepi. Hasil Output citra prewitt masih banyak terlihat titik noise. Sangat dianjurkan uji coba hasil pendeteksian tepi untuk memperoleh hasil yang diinginkan.

\section{REFERENSI}

[1] E. R. Kuswandi and N. Fadillah, "Perbandingan Metode Robert dan Metode Prewitt untuk Deteksi Tepi pada Citra Tanda Tangan," InfoTekJar (Jurnal Nas. Inform. dan Teknol. Jaringan), vol. 3, no. 2, pp. 155-158, 2019, doi: 10.30743/infotekjar.v3i2.997.

[2] K. Arwana, P. Kasih, and M. Kom, "ARTIKEL FLEKSIBEL Oleh: Dibimbing oleh: UNIVERSITAS NUSANTARA PGRI KEDIRI SURAT PERNYATAAN ARTIKEL SKRIPSI TAHUN 2017," vol. 01, no. 04, 2017.

[3] G. F. Laxmi, P. Eosina, and F. Fatimah, "Analisis perbandingan metode prewitt dan canny untuk identifikasi ikan air tawar," Pros. SINTAK, pp. 201-206, 2017.

[4] W. Supriyatin, "Perbandingan Metode Sobel, Prewitt, Robert dan Canny pada Deteksi Tepi Objek Bergerak," Ilk. J. Ilm., vol. 12 , no. 2 , pp. 112-120, 2020, doi: 10.33096/ilkom.v12i2.541.112-120.

[5] I. G. N. Suryantara, "Implementasi Deteksi Tepi Untuk Mendeteksi Keretakan Tulang Orang Lanjut Usia (Manula) Pada Citra Rontgen Dengan Operator Sobel Dan Prewitt," J. Algoritm. Log. dan Komputasi, vol. 1, no. 2, pp. 5160, 2018, doi: 10.30813/j-alu.v1i2.1368.

[6] G. F. Laxmi, P. Eosina, and F. Fatimah, "Implementasi Penggabungan Prewitt dan
Canny Edge Detection untuk Identifikasi Ikan Air Tawar," Krea-Tif, vol. 6, no. 2, p. 120, 2018, doi: 10.32832/kreatif.v6i2.2185.

[7] R. Sistem, M. A. Masril, and R. Noviardi, "Analisa Morfologi Dilasi untuk Perbaikan Kualitas Citra Deteksi Tepi pada," vol. 1, no. 10, pp. 9-11, 2021.

[8] V. Lusiana, "Deteksi Tepi pada Citra Digital menggunakan Metode Kirsch dan Robinson," J. Teknol. Inf. Din., vol. 18, no. 2, pp. 182-189, 2019.

[9] A. Pranata and E. Z. Astuti, "Pengolahan Citra Berbasis Deteksi Tepi Prewitt Pada Gambar Gigi Manusia," Eksplora Inform., vol. 6, no. 2, pp. 98-105, 2017.

[10] B. Niam and Q. Qirom, "Deteksi Tulang Retak Dengan Metode Deteksi Tepi Prewitt," Power Elektron. J. Orang Elektro, vol. 8, no. 2, pp. 25-28, 2019, doi: 10.30591/polektro.v8i2.1403.

[11] R. J. Sexton et al., "No Titleبيبيب,",

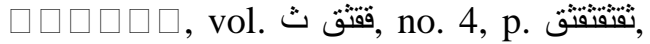
2018.

[12] B. Sitohang and A. Sindar, "Analisis Dan Perbandingan Metode Sobel Edge Detection Dan Prewit Pada Deteksi Tepi Citra Daun Srilangka," J. Nas. Komputasi dan Teknol. Inf., vol. 3, no. 3, pp. 314322, 2020, doi: 10.32672/jnkti.v3i3.2511. 